\title{
Integration of human papillomavirus types 16 and 18 in cervical adenocarcinoma
}

\author{
K Cooper, C S Herrington, E S-F Lo, M F Evans, J O'D McGee
}

\begin{abstract}
Aims: To determine which type of human papillomavirus (HPV) is associated with cervical adenocarcinoma and whether the virus was integrated or episomal in two continents.

Methods: Biopsy specimens from the UK $(n=16)$ and South Africa $(n=22)$ were analysed by non-isotopic in situ hybridisation (NISH) for HPV types 6, $11,16,18,31,33$, and 35 on archival biopsy specimens using digoxigenin labelled probes.

Results: A total of 20 adenocarcinomas (53\%) from both groups contained HPV DNA. In the UK group, seven and four cases contained HPV $18(44 \%)$ and 16 (25\%) respectively. In the South African group, nine cases contained HPV 18 (41\%) while HPV DNA was not detectable in the other 13 cases. Hence HPV 18 was present in $80 \%$ of HPV positive adenocarcinomas.

Conclusions: The HPV 16 or 18 genome was integrated in all viral positive cases. In two cases HPV 18 was also present in an episomal form. These data indicate that HPV integration is common to cervical adenocarcinoma in two continents by the same methodology. The lower prevalence of HPV 18 detection in the South African group may have been due to the presence of other or unsequenced HPV types.
\end{abstract}

The association between HPV and genital intraepithelial neoplasia and invasive malignancy has resulted in over 20 genotypes being identified in the genital tract within the last decade (for review see de Villiers). ${ }^{1}$ The majority of these HPV types were isolated from neoplastic squamous epithelium. More recently there has been increasing interest in the association between HPV and glandular neoplasia of the cervix. In 1988 it was shown that HPV DNA was found as frequently in adenocarcinoma and adenosquamous cancer as in squamous cell cancer of the cervix. ${ }^{2}$ It was also demonstrated that HPV18 was the predominant HPV type in adenocarcinoma. Although the latter association has been confirmed in other studies, ${ }^{3-13}$ two reports from the UK failed to show a significant association. ${ }^{14} 15$
HPV DNA is present in three morphologically distinct forms in the nuclei of cervical intraepithelial neoplasia (CIN) and cervical squamous cell cancer (SCC) by nonisotopic in situ hybridisation (NISH). ${ }^{1617}$ These NISH signal types have been designated 1-3. It was postulated that the type 1 signal represents episomal virus, type 2 integrated virus, and type 3 a combination of both. This hypothesis has been strengthened by the demonstration that these NISH signal types correlate with episomal and integrated virus in a combined in situ and filter hybridisation study. ${ }^{18}$ This approach to defining the physical state of the HPV genome (unlike Southern blotting) can be applied to retrospective studies of archival biopsy specimens.

The aims of this study were twofold: (i) to determine by NISH signal pattern whether HPV is integrated, or otherwise, in cervical adenocarcinoma; (ii) to investigate and compare the prevalence of HPV DNA in cervical adenocarcinoma from South Africa (Durban) and the UK (Oxford).

\section{Methods}

BIOPSY MATERIAL

Archival formalin fixed paraffin wax embedded cervical biopsy specimens of adenocarcinomas $(n=22)$ were obtained from the surgical files of King Edward VIII Hospital, Durban, South Africa (SA) from 1988. The British group of adenocarcinoma biopsy specimens ( $\mathrm{n}$ $=16$ ) were from the archival files of this department from 1982 to 1991. Parallel haematoxylin and eosin slides of the adenocarcinomas were reviewed by a consultant histopathologist and classified according to morphological subtype. ${ }^{19}$

NISH

NISH was performed using digoxigenin labelled genomic probes for HPV $6,11,16$, $18,31,33$, and 35 as previously described for HPV detection in CIN and squamous cell cancer (SCC).$^{1620}$ Biopsy specimens (of CIN or SCC) known to contain HPV16 and 18 were analysed in parallel with each batch of cases as positive controls.

\section{Results}

NISH GENOTYPING OF HPV

A total of 20 adenocarcinomas (53\%) from
Correspondence to:

Accepted for publication

30 October 1991 
Table Adenocarcinoma differentiation and HPV genotyping

\begin{tabular}{|c|c|c|c|c|c|c|}
\hline \multirow[b]{2}{*}{ Adenocarcinoma subtype } & \multicolumn{2}{|c|}{ HPV16 } & \multicolumn{2}{|c|}{$H P V 18$} & \multicolumn{2}{|c|}{ HPV negative } \\
\hline & $U K$ & $S A$ & $U K$ & $S A$ & $U K$ & $S A$ \\
\hline $\begin{array}{l}\text { Well differentiated } \\
\text { Moderately differentiated } \\
\text { Poorly differentiated }\end{array}$ & $\begin{array}{l}3 \\
0 \\
1\end{array}$ & $\begin{array}{l}\mathbf{0} \\
\mathbf{0} \\
\mathbf{0}\end{array}$ & $\begin{array}{l}4 \\
1 \\
2\end{array}$ & $\begin{array}{l}6 \\
1 \\
2\end{array}$ & $\begin{array}{l}5 \\
0 \\
0\end{array}$ & $\begin{array}{l}5 \\
1 \\
7\end{array}$ \\
\hline
\end{tabular}

both groups contained HPV DNA. In the UK group, seven cases (44\%) and four cases (25\%) contained HPV 18 and 16 respectively. In the SA group, nine cases contained HPV $18(41 \%)$. Overall therefore, HPV 18 was present in $80 \%$ of the HPV positive adenocarcinomas (table). In addition six of the viral positive adenocarcinomas had an adjacent adenocarcinoma in situ component, of which four contained HPV DNA. The virus was not detected in the morphologically normal glands adjacent to adenocarcinomas in three cases.

NISH SIGNAL TYPE

All the HPV DNA positive adenocarcinomas contained a type $2 \mathrm{NISH}$ signal-that is a punctate/dot signal within the nucleus (fig 1). In addition a type 3 signal was present in two cases from the UK (fig 2). Although two adenocarcinomas showed an NISH signal in the majority of cells, most adenocarcinomas contained an NISH signal in focal collections of tumour cells. The two cases that contained a type 3 NISH signal pattern were well differentiated adenocarcinomas. The four viral positive cases with an adenocarcinoma in situ component contained a type 2 NISH signal.

\section{CORRELATION OF ADENOCARCINOMA}

MORPHOLOGY AND HPV TYPE

The tumour morphology and HPV types are summarised in the table. HPV 16 was not detected in any of the $22 \mathrm{SA}$ cases. In both the UK and SA HPV positive cases (20) there was no significant correlation between HPV status and differentiation. It should be noted however that the majority of the poorly differentiated adenocarcinomas in the SA group did not contain any of the HPV types probed for in this study while the three poorly dif-

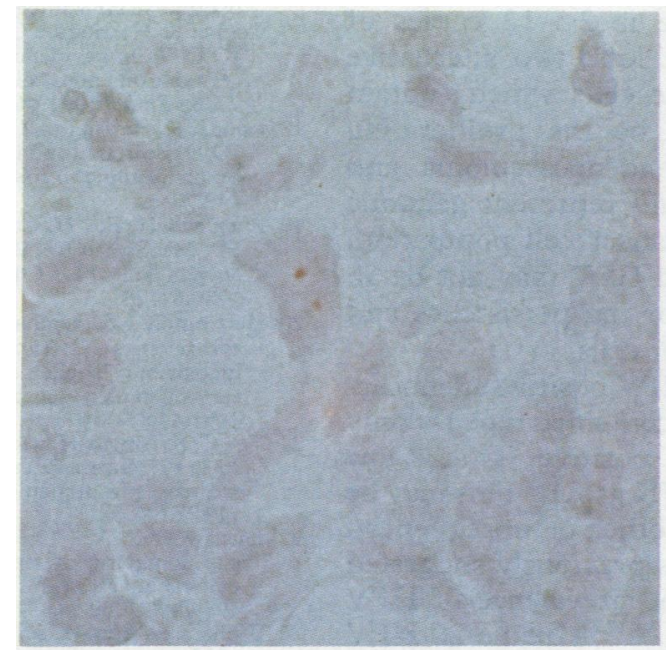

Figure 1 NISH type 2 signal in the form of punctate/ dots in a tumour cell of cervical glandular origin. ferentiated UK cases contained HPV 16 or 18 .

No tumour from the UK or SA groups hybridised with HPV $6,11,31,33$, or 35 . Apart from indicating that these viruses were not detectable in cervical adenocarcinoma the data also indicate the specificity of the reactions with HPV 16 and 18.

\section{Discussion}

It was shown recently by NISH that HPV DNA is present in three morphologically distinct forms in the nuclei of CIN and SCC. ${ }^{16} 17$ These are referred to as NISH signal types 1,2 , and 3. A type 1 signal is diffuse throughout the nucleus, a type 2 signal is punctate, and type 3 is a combination of type 1 and 2 . It was postulated that a type 1 signal represents episomal virus, type 2 integrated virus, and type 3 a combination of both. ${ }^{16-17}$ An NISH type 1 signal occurs in koilocytes and keratinising squamous cells which express capsid protein suggesting that it represents episomal HPV. There are four types of evidence indicating that a type 2 signal represents integrated HPV. This NISH signal is present in: CaSki and HeLa cell lines which contain integrated HPV 16 and 18 respectively; ${ }^{21}$ it is evident on sister chromatids in SCC biopsy specimens; ${ }^{17}$ a type 2 signal was present in $59 \mathrm{HPV}$ positive SCC from two geographic locales irrespective of whether the HPV was type 16,18 , or $33 ;^{17}$ there was an absolute correlation between an NISH type 2 signal and the presence of integrated HPV on Southern blot analysis of DNA from the same CIN and SCC biopsy specimens. ${ }^{18} \mathrm{By}$ analogy with this evidence a type 2 NISH signal in $53 \%$ of adenocarcinomas from two different countries indicates that HPV 16 or 18 are also integrated in this cancer type.

The presence of HPV 18 in $80 \%$ of both SA and UK HPV positive adenocarcinomas further illustrates the strong association between HPV 18 and this cancer type in two geographical regions. The predominance of HPV $18(44 \%)$ over HPV $16(25 \%)$ in the UK group is compatible with most other Western studies. Two studies from different centres in the USA

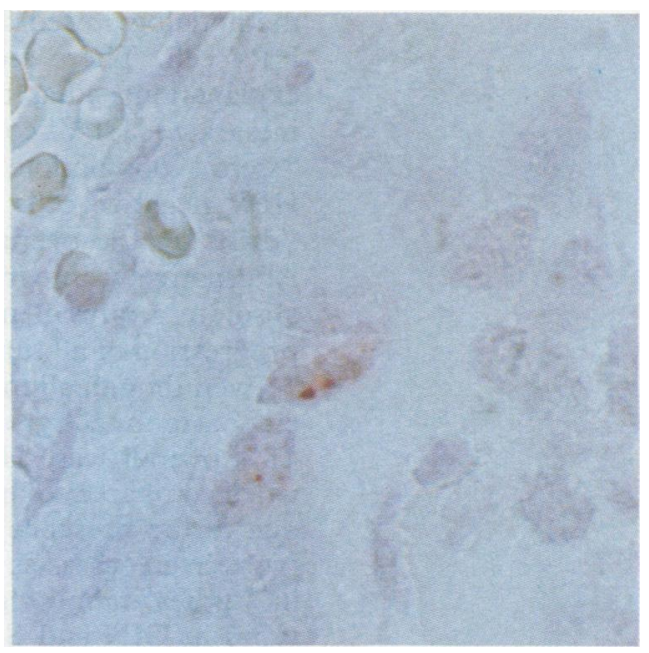

Figure 2 Combined punctate and diffuse signals (NISH type 3) in cervical adenocarcinoma cells. 
employing in situ hybridisation (ISH), showed HPV DNA in $42.5 \%(17 / 40)^{2}$ and $83 \%(5 / 6)^{5}$ of cervical adenocarcinomas. HPV 18 was the predominant type in both studies. In Finland HPV 16 and 18 were found in $18 \%$ (19 of 106) of adenocarcinomas, with HPV 18 in 17 of these cases $;^{13}$ and in Japan several types of HPV DNA were detected in $46.7 \%(15 / 32)$ of cervical adenocarcinomas, ten of which contained HPV $18 .{ }^{8}$ Using a cocktail of HPV 16/18 biotinylated DNA probes, 4/11 adenocarcinomas and $4 / 4$ in situ adenocarcinomas from Denmark, contained HPV sequences by in situ hybridistion; in contrast HPV 16/18 were not detectable in endometrial adenocarcinomas infiltrating cervical tissue. ${ }^{6}$ Similar incidence figures $(64-89 \%)$ have been found in the USA for in situ and microinvasive adenocarcinomas. $^{3422}$ It would seem that not only is invasive adenocarcinoma associated with HPV infection but so are its presumed precursors, adenocarcinoma in situ and microinvasive adenocarcinomas. The four cases of HPV positive adenocarcinoma in situ in this study would support this association.

In contrast to these and other results, two recent UK studies have suggested that HPV infection is not associated with adenocarcinoma of the uterine cervix. HPV 16 and 18 were demonstrated in $6.3 \%$ of adenocarcinoma and $12.5 \%$ of in situ adenocarcinoma by NISH, and in $31 \%$ of adenocarcinoma by polymerase chain reaction (PCR) ${ }^{14}$ In the other study no HPV DNA was detected by NISH in adenocancers. ${ }^{15}$ Whether this is due to geographic variation or methodological differences is not clear. An integrated NISH type 2 signal can often only be confidently observed where the NISH signal (red) at high magnification and the nucleus (blue) are clearly defined in two distinct contrasting colours as shown here (fig 1); only the minority of cells present in adenocarcinomas are HPV positive by NISH. This may explain the low prevalence of HPV in the previous in situ hybridisation studies.

The absence of HPV from the majority of cells in adenocarcinoma could be due to insufficient sensitivity of the NISH procedure to pick up one viral copy or fragments of the HPV genome. The sensitivity of the NISH methodology used here is $2 \cdot 5-12$ copies of $\mathrm{HPV} /$ cell. There are at least two alternative explanations-that those cells which contain integrated HPV could be the proliferating "stem" population in adenocarcinoma and HPV negative cells could represent genomic "drift" in the overall cancer cell population. Alternatively, integrated HPV may not be an absolute requirement for the persistence and progression of all tumour cells.

Even though all the HPV positive adenocarcinoma in the SA group contained type 18 , only $41 \%$ overall were HPV positive. This is low when compared to the UK group. This may be due to the presence of other or unsequenced types in SA cases as was previously suggested in studies examining the prevalence of HPV types in CIN and SCC. ${ }^{16}{ }^{17}$ In the $20 \mathrm{HPV}$ positive tumours there was no correlation between tumour differentiation and viral infec- tion, as was implied in a previous study which combined both SCC and adenocarcinoma. ${ }^{9}$

K C is an Oxford Nuffield Medical Fellow. This work was supported by grants to J O'D McG from the Cancer Research Campaign (UK). We are grateful to Dr G Orth for the HPV 33 probe and Dr A T Lorincz for the HPV 31 and 35 probes.

1 De Villiers E-M. Heterogeneity of the human papillomavirus group. J Virol 1989;63:4898-903

2 Tase T, Okagaki T, Clark BA, et al. Human papillomavirus types and localisation in adenocarcinoma and adenosquamous carcinoma of the uterine cervix: A study by in squamous carcinoma of the uterine cervix: A
situ hybridisation. Cancer Res $1988 ; 48: 993-8$.

3 Tase T, Okagaki T, Clark BA, Twiggs LB, Ostrow RS Faras AJ. Human papillomavirus DNA in adenocarcinoma in situ and microinvasive adenocarcinoma of the uterine cervix and coexisting cervical squamous intraepithelial neoplasia. Int J Gynecol Pathol 1989;8 8-17.

4 Okagaki T, Tase T, Twiggs LB, Carson LF. Histogenesis of cervical adenocarcinoma with reference to human papillomavirus-18 as a carcinogen. $J \operatorname{Rep} M e d$ 1989;34: 639-44.

5 Gordon AN, Bornstein J, Kaufman RH, et al. HPV associated with adenocarcinoma and adenosquamous carcinoma of the cervix: Analysis by in situ hybridisation. Gynaecol Oncol 1989;35:345-8.

6 Nielson AL. HPV type 16/18 in uterine cervical adenocarcinoma in situ and adenocarcinoma: A study by in situ hybridisation with biotinylated DNA probes. Cancer 1990;65:2588-93.

7 Yoshikawa H. Virological studies on generation of cervical carcinomas. Acta Obstet Gynaecol Jpn 1990;42:834-43 (in Japanese, English abstract).

$8 \mathrm{Nagai}$ N. Molecular biologic study on the carcinogenesis of HPV in uterine cervical cancer and related lesions: analysis of HPV types 16, 18 E6/E7 gene mRNA Acto Obstet Gynaecol Jpn 1990;42:823-33 (in Japanese, English abstr).

9 Barnes W, Delgrado G, Kurman RJ, et al. Possible prognostic significance of human papillomavirus type in cervical tic significance of human papillomavir
cancer. Gynecol Oncol 1988;29:267-73.

10 Wilzynski SP, Walker J, Liao S, Bergen M. Adenocarcinoma of the cervix associated with human papillomavirus. Cancer 1988;62:1331-6.

11 Wilzynski SP, Bergen M, Walker J, Liao S, Pearlman LF Human papillomavirus and cervical cancer. Analysis of histopathologic features associated with different viral types. Hum Pathol 1988;19:697-704.

12 Smotkin D, Berek JS, Fu YS, Hacker WF, Major FJ, Wettstein FO. Human papillomavirus deoxyribonucleic acid in adenocarcinoma and adenosquamous carcinoma of the cervix. Obstet Gynecol 1986;68:241-4.

13 Leminen A, Paavonen J, Vesterinen E, Wahlstrom T, Rantala I, Lehtinen M. Human papillomavirus type 16 Rantala 1 , Lehtinen $M$. Human papillomavirus type 16 and 18 adenocarcinoma

14 Griffin NR, Dockey D, Lewis FA, Wells M. Demonstration of low frequency of HPV DNA in cervical adenocarcinoma and adenocarcinoma in situ by the polymerase chain reaction and in situ hybridisation. Int J Gynecol Patho 1991;10:36-43.

15 Young FI, Ward LM, Brown LJR. Absence of human papillomavirus in cervical adenocarcinoma determined by in situ hybridisation. J Clin Pathol 1991;44:340-1.

16 Cooper K, Herrington CS, Graham AK, Evans MF, McGee JO'D. In situ HPV genotyping of cervical intraepithelial neoplasia in South African and British patients: Evidence neoplasia in South African and British patients: Evidence
of putative HPV integration. J Clin Pathol 1991;44:400-5.

17 Cooper K, Herrington CS, Graham AK, Evans MF, McGee JO'D. In situ evidence for HPV 16, 18, 33 integration in cervical squamous cell cancer in Britain and South Africa. J Clin Pathol 1991;44:406-9.

18 Cooper K, Herrington CS, Stickland JE, Evans MF, McGee JO'D. Episomal and integrated HPV in cervical neoplasia by nonisotopic in situ hybridisation. J Clin Pathol 1991 44:990-6.

19 Buckley CH, Fox H. Carcinoma of the cervix. In: Anthony PP, MacSween RNM, eds. Recent advances in histopathology. Vol 14. Churchill Livingstone, Edinburgh. 1989:63-78.

20 Herrington CS, Graham AK, McGee JO'D. Interphase cytogenetics III: Increased sensitivity and flexibility of digoxigenin labelled DNA probes for HPV detection in cervical biopsy specimens and cell lines. $J$ Clin Pathol 1991;44:33-8.

21 Yee C, Krishnan-Hewlett I, Baker CC, Schlegel R, Howley PM. Presence and expression of human papillomavirus sequences in human cervical cell lines. A J Pathol 1985; 119:361-6.

22 Farnsworth A, Laverly C, Stoler MH. Human papillomavirus messenger RNA expression in adenocarcapilomavirus messenger RNA expression in adenocar1989;4:321-30.

23 Williamson Anna-Lise, Dehaecek CMC, Soeters R. Typing of Human papillomavirus in cervical intraepithelial neoplasia grade 3 biopsies from Cape Town. J Med Viro 1989;28:146-9. 